\title{
A Facile Procedure for the Conversion of Oximes to Ketones and Aldehydes with Potassium Dichromate in Dimethylformamide under Homogeneous Conditions
}

\author{
LI-HONG HUANG ${ }^{1}$, JI-DONG LOU ${ }^{1,2, *}$, CHANGHE ZHANG $^{3}$, \\ FANG LIN ${ }^{1}$, AND XIAO-NAN ZOU ${ }^{1}$ \\ ${ }^{1}$ College of Life Sciences, China Jiliang University, Hangzhou, Zhejiang 310018, China \\ ${ }^{2}$ Sirnaomics, Inc., 401 Professional Drive, Gaithersburg, MD 20879, USA \\ ${ }^{3}$ Centre for the Research and Technology of Agro-environmental and Biological Sciences \\ (CITAB)/Department of Biology and Environment, Universidade de Trás-os-Montes e Alto \\ Douro (UTAD), Apartado 1013, 5001-801 Vila Real, Portugal \\ jidonglou@sirnaomics.com \\ Received 07 October 2011; Accepted 03 December 2011

\begin{abstract}
Oxidative cleavage of oximes to their parent corresponding carbonyl compounds using potassium dichromate-dimethylformamide system under homogeneous conditions in good yields is described. The main advantage of the present method is no need of preparation of hexavalent chromium-based reagents due to using a polar aprotic solvent.
\end{abstract}

Keywords: carbonyl compounds, dimethylformamide, oxidative cleavage, oximes, potassium dichromate.

\section{Introduction}

Oximes have great potential as intermediates in organic chemistry, especially as useful protecting groups for the carbonyl compounds, and are easily obtained from their parent carbonyl compounds [1, 2]. Regeneration of carbonyl compounds from the oxime derivatives is an important process in synthetic organic chemistry, for instance, regeneration by the way of hydrolytic, reductive, and oxidative reactions [3]. However, only a limited number of methods or reagents are available for the conversion of oximes to the corresponding carbonyl compounds under mild reaction conditions. Therefore, there has been considerable interest in the development of mild techniques for this transformation.

The most important procedure for the regeneration of their corresponding carbonyl compounds from the oxime is oxidative cleavage reaction, which has been accomplished by a variety of chromium (VI) based reagents, such as Jones reagent [4], methylammonium chlorochromate-Alumina [5], chromium trioxide-silica gel [6], pyridinium fluorochromate [7], quinolinium dichromate [8], potassium dichromate [9], pyridinium fluorochromatehydrogen peroxide [10], 2,6-dicarboxypyridinium chlorochromate [11], $\gamma$-picolinium chlorochromate [12], benzyltriphenylphosphonium chlorochromate [13], quinolinium fluorochromate [14], tetramethylammonium fluorochromate (VI) [15], benzyltrimethylammonium fluorochromate (VI) [16], imidazolium dichromate [17], 
dicarboxypyridinium fluorochromate [18], tetrabutylammonium chromate [19], chromic acid [20], chromium trioxide- $\mathrm{NaHSO}_{4} \bullet \mathrm{H}_{2} \mathrm{O}$ [21], glycinium chlorochromate-silica gel [22], ammonium chlorochromate-montmorillonite K10 [23], etc. Most of them are carried out under either heterogeneous conditions or solvent-free/solid state conditions. Meanwhile, the reagents used are often expensive, or use not readily available reagents or reagents which need to be freshly prepared. In addition, only few studies on deoximation with hexavalent chromium derivatives under homogeneous conditions have been reported.

\section{Experimental}

Oxidative cleavage of benzophenone oxime to benzophenone; Typical Procedure:

Benzophenone oxime (197 mg, $1 \mathrm{mmol})$ in DMF $(10 \mathrm{~mL})$ was placed in a flask, which was stirred with a magnetic stirrer. And a solution of potassium dichromate $(588 \mathrm{mg}, 2 \mathrm{mmol})$ in DMF $(10 \mathrm{~mL})$ was added dropwise. Care was taken to maintain the temperature of the reaction mixture at $65-70{ }^{\circ} \mathrm{C}$. The progress of the reaction was monitored by TLC (plates: aluminum-backed silica gel Merck $\left.60 \mathrm{GF}_{254}\right)$ using hexane:ethyl acetate (7:3) as an eluent. After $1 \mathrm{~h}$ the crude product was obtained, which crude product was then purified by preparative TLC with hexane:ethyl acetate (7:3) to afford $169 \mathrm{mg}(93 \%)$ benzophenone.

\section{Results and Discussion}

Previously, we found that potassium dichromate $\left(\mathrm{K}_{2} \mathrm{Cr}_{2} \mathrm{O}_{7}\right)$ is easily dissolved in a polar aprotic solvent, N,N-dimethylformamide (DMF), and it is a good system for selective oxidation of alcohols into corresponding aldehydes and ketones [24], and oxidation of benzoins into corresponding benzils [25], respectively, under homogeneous conditions. As a part of our ongoing program related to develop new oxidation methods we now report here the oxidative cleavage of oximes (1) to their corresponding carbonyl compounds (2) using our reported $\mathrm{K}_{2} \mathrm{Cr}_{2} \mathrm{O}_{7}$-DMF system (Scheme 1), which is an extension of application for $\mathrm{K}_{2} \mathrm{Cr}_{2} \mathrm{O}_{7}$-DMF oxidation.

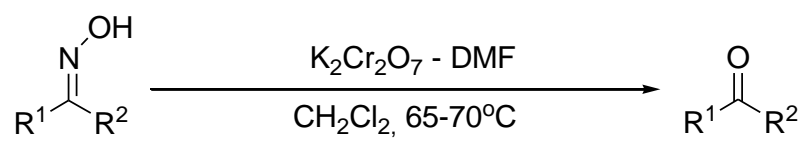

(1)

(2)

\section{Scheme 1}

In the present procedure, a 1 to 2 molar ratio of the substrate to the oxidant is employed. After potassium dichromate is stirred with oximes in DMF at around $65-70{ }^{\circ} \mathrm{C}$, the corresponding carbonyl compounds are obtained in good yields. Of this oxidation procedure, both potassium dichromate and $\mathrm{N}, \mathrm{N}$-dimethyl formamide are readily commercial available and inexpensive, and they can be used directly for the reaction without further purification. The progress of the oxidation is monitored with TLC, and the product is purified by preparative TLC. The oxidized products are all known compounds and identified by spectroscopic comparison with authentic samples. Our results are reported in the Table 1.

Comparing with most of the reported procedures for the oxidative cleavage of oximes to their corresponding carbonyl compounds with hexavalent chromium derivatives, the main advantages of the present method is no need of preparation of hexavalent chromium-based reagent. In addition, because the reaction is carried out in polar aprotic solvent, it can be performed under homogeneous conditions. Furthermore, the present method offers additional advantages in term of simplicity of performance, comparatively mild reaction conditions, and good yields. 
Table 1. Oxidative cleavage of oximes to their corresponding carbonyl compounds with potassium dichromate-dimethyl formamide under homogeneous conditions.

\begin{tabular}{|c|c|c|c|c|}
\hline Entry & Oxime & Time (h) & Product $^{\mathrm{a}}$ & Yield $^{\mathrm{b}}(\%)$ \\
\hline 1 & & 1 & & 93 \\
\hline 2 & & 1.5 & & $c 89$ \\
\hline 3 & & 2 & & 86 \\
\hline 4 & & 2 & & 90 \\
\hline 5 & & 1.5 & & 86 \\
\hline 6 & & 2.5 & & 80 \\
\hline 7 & & 2.5 & & 92 \\
\hline 8 & & 1.5 & & 86 \\
\hline 9 & & 3 & & 82 \\
\hline 10 & & 3 & & 82 \\
\hline
\end{tabular}

${ }^{\mathrm{a}}$ All products were identified by comparison of their physical and spectral data with those of authentic samples.

${ }^{\mathrm{b}}$ Yield of isolated pure product. 


\section{Conclusion}

Efficient oxidative cleavage of oximes to their parent carbonyl compounds using potassium dichromate-dimethylformamide system under homogeneous conditions in the yield between 82 and $93 \%$ is described. The main advantage of the present method is no need of preparation of hexavalent chromium-based reagent. The present procedure is an extension of our previous work as well.

\section{References}

1. Green T W and Wuts P Protective Groups in Organic Synthesis; 2nd ed. Wiley: New York, 1991.

2. Cheronis N D and Entrikin J B Identification of Organic Compounds; Interscience: New York, 1963.

3. Sahu S, Sahu S, Patel S, Dash S and Mishra B K Indian J. Chem, 2008, 47B, 259.

4. Araujo H C, Ferreira G A L and Mahajan J R J. Chem. Soc., Perkin Trans. 1, 1974, 2257.

5. Zhang G, Yang D, Chen M and Cai K Synth. Commun. 1998, 28, 607.

6. Bendale P M and Khadilkar B M Synth. Commun. 2000, 30, 665.

7. Bhandari A, Mishra P and Banerji K K React. Kinet. Catal. Lett. 2000, 71, 343.

8. Sadeghi M M, Mohammadpoor-Baltork I, Azarm M and Mazidi M R Synth. Comm. 2001, 31, 435.

9. Mohammadpoor-Baltork I, Sadeghi M M and Adibi A-H Molecules, 2001, 6, 900.

10. Ganguly N C, Sukai A K, De S and De P Synth. Comm., 2001, 31, 1607.

11. Hosseinzadeh R, Tajbakhsh M and Niaki M Y Tetrahedron Lett., 2002, 43, 9413.

12. Salehi P, Khodaei M M and Goodarzi M Synth. Commun., 2002, 32, 1259.

13. Hajipour A R, Mallakpour S E, Mohammadpoor-Baltork I and Backnejad H Indian J. Chem, 2002, 41B, 1740.

14. Tajbakhsh M, Mohammadpoor-Baltork I and Ramzanian-Lehmali F J. Chem. Res. (S), 2003, 710 .

15. Mahjoub A R, Ghammami S and Kassaee M Z Tetrahedron Lett. 2003, 44, 4555.

16. Kassaee M Z, Hattami M and Moradi L Acta Chim. Slov., 2004, 51, 743.

17. De S K Synth. Comm., 2004, 34, 2751.

18. Tajbakhsh M, Hosseinzadeh R, Ramzanian-Lahmali F and Sadatshahabi Marzieh $J$. Chin. Chem. Soc., 2005, 52, 1005.

19. Pourali A R and Goli A Bull. Korean Chem. Soc., 2006, 27, 587.

20. Ali M H, Greene S, Wiggin C J and Khan S Synth. Commun. 2006, 36, 1761.

21. Shirini F, Mamaghani M and Rahmanzadeh A ARKIVOC 2007 (i) 34.

22. Shoar R H, Rezael A, Haghighi M, Ojgaz A J, Khosroshahi M and Javadi N M Asian J. Chem., 2007, 19, 2901.

23. Li J and Meng X E-Journal of Chemistry, 2009, 6, 156.

24. Lou J D, Lu L and Liu W Synth. Commun. 1997, 27, 3701.

25. Lou J D, Lin F, Zhang C, Wang Q and Zou X Oxid. Commun. 2011, 34, 540. 


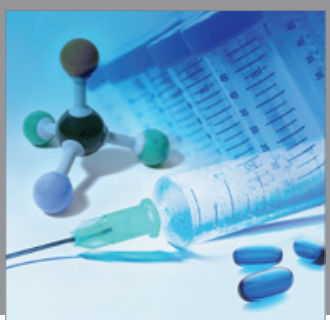

International Journal of

Medicinal Chemistry

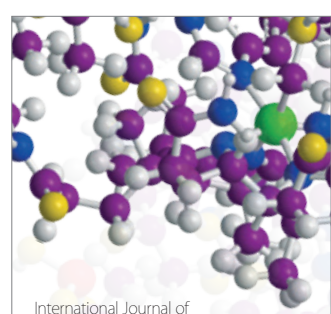

Carbohydrate Chemistry

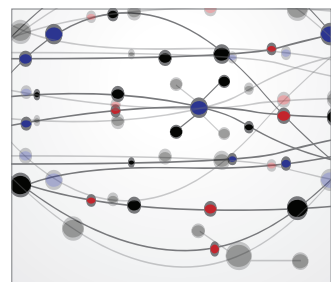

The Scientific World Journal
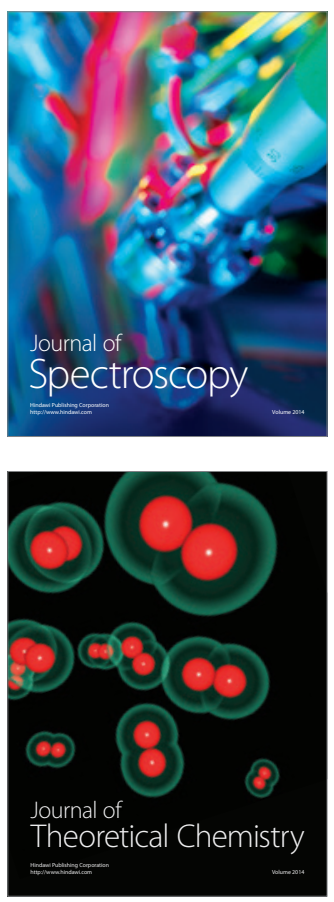
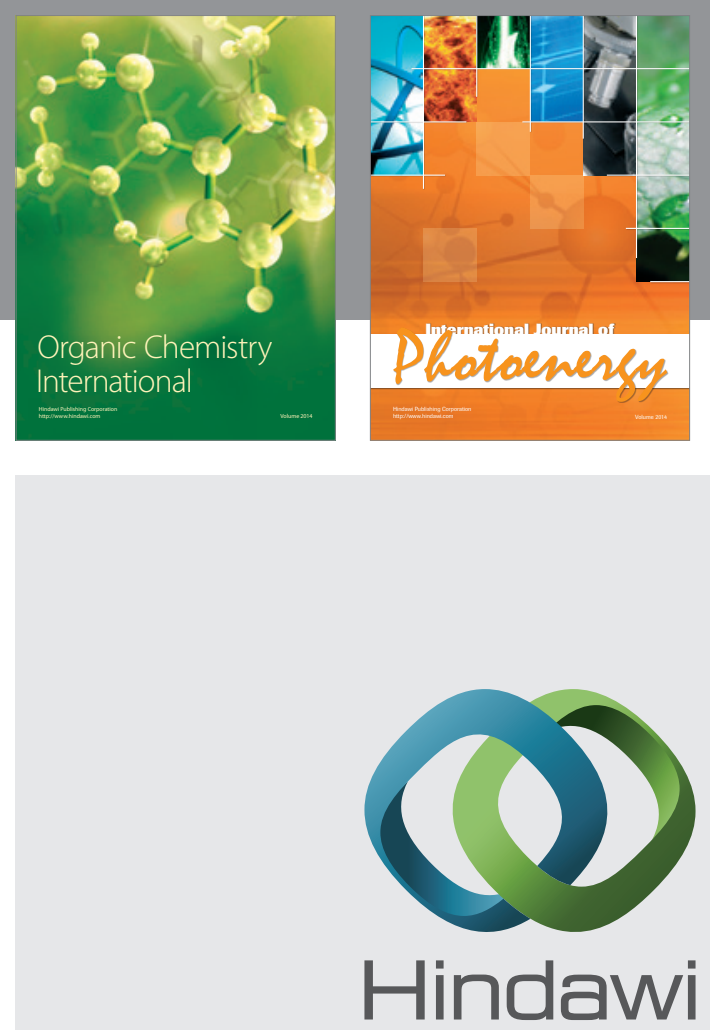

Submit your manuscripts at

http://www.hindawi.com
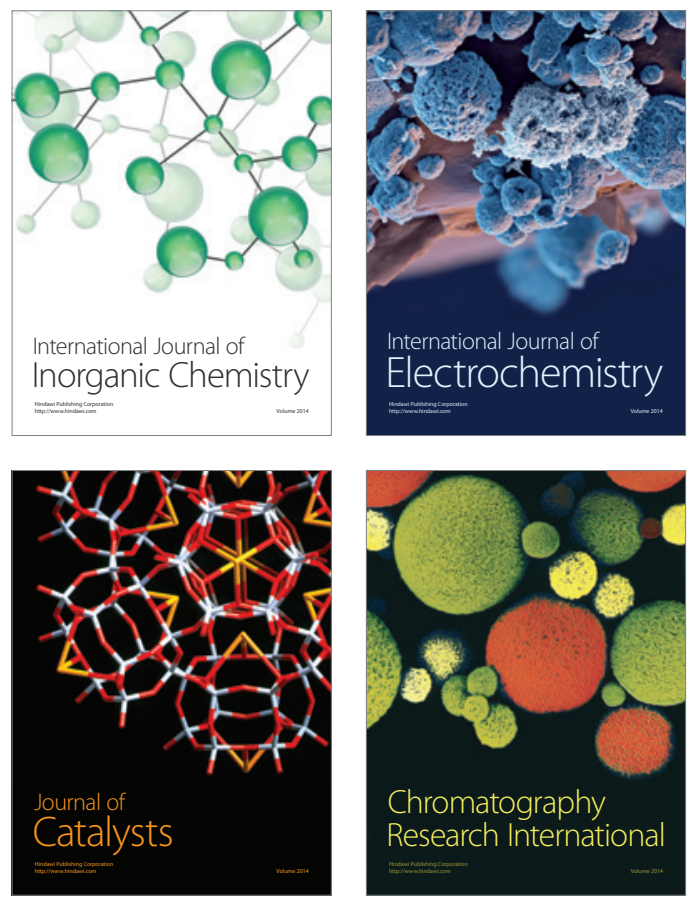
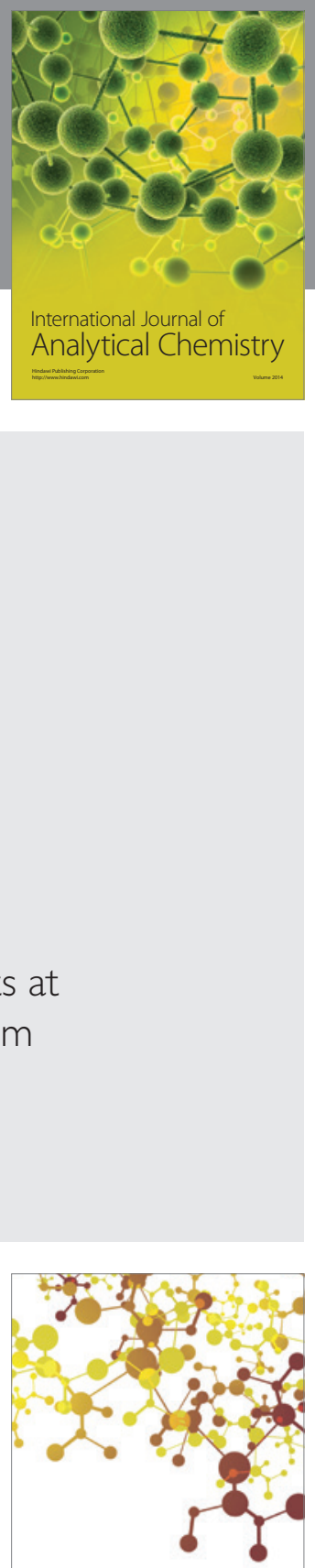

Journal of

Applied Chemistry
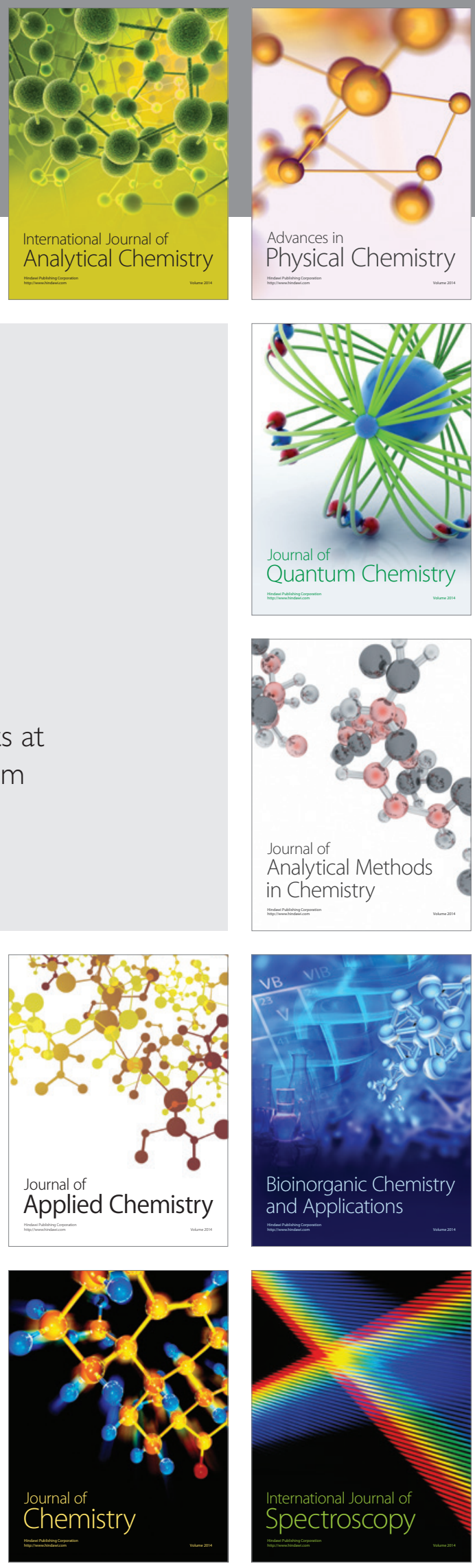